
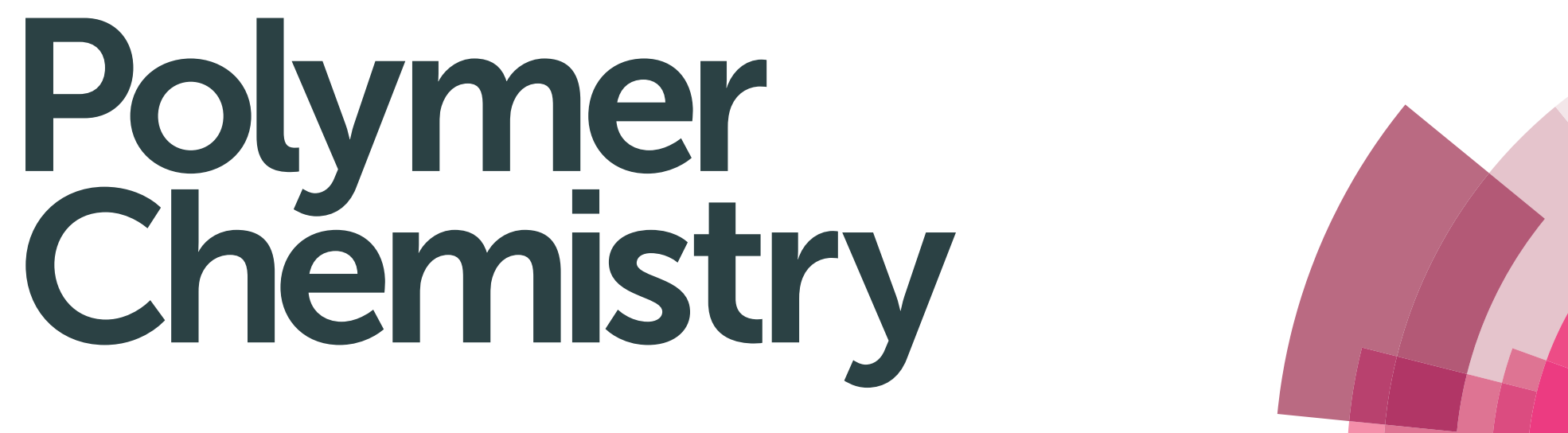

www.rsc.org/polymers

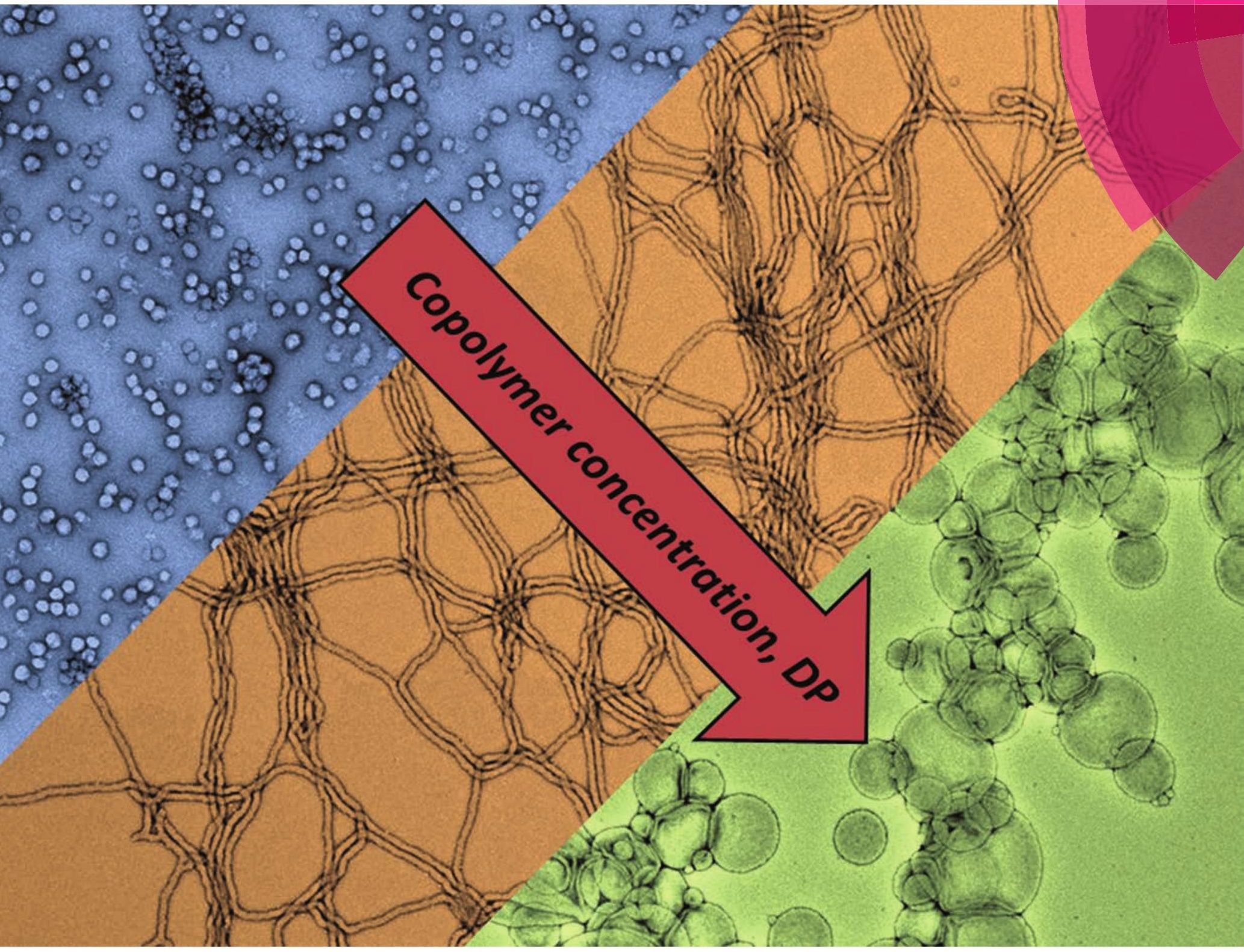

ISSN 1759-9954

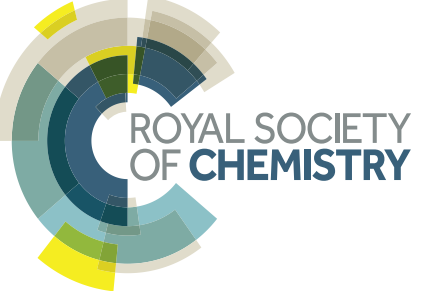




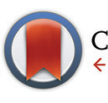

CrossMark \& click for updates

Cite this: Polym. Chem., 2015, 6, 7264

Received 18th March 2015 Accepted 10th April 2015

DOI: $10.1039 / c 5 p y 00396 b$ www.rsc.org/polymers

\title{
Polysulfobetaine-based diblock copolymer nano- objects via polymerization-induced self-assembly $\dagger$
}

\author{
Kay E. B. Doncom, Nicholas J. Warren and Steven P. Armes*
}

\begin{abstract}
A zwitterionic polysulfobetaine-based macromolecular chain transfer agent $\left(\mathrm{PSBMA}_{38}\right)$ was prepared by reversible addition-fragmentation chain transfer (RAFT) solution polymerization of [2-(methacryloyloxy)ethyl] dimethyl(3-sulfopropyl) ammonium hydroxide (SBMA) in an aqueous solution containing $0.5 \mathrm{M}$ $\mathrm{NaCl}$ at $70{ }^{\circ} \mathrm{C}$. This PSBMA 38 macro-CTA was then utilized for the RAFT aqueous dispersion polymerization of a water-miscible monomer, 2-hydroxypropyl methacrylate (HPMA). The growing PHPMA block became hydrophobic in situ, leading to polymerization-induced self-assembly. Systematic variation of the mean degree of polymerization of the PHPMA block and the copolymer concentration enabled access to pure phases of spheres, worms or vesicles, as judged by transmission electron microscopy and dynamic light scattering studies. A detailed phase diagram was constructed and the thermo-responsive behavior of selected $\mathrm{PSBMA}_{38}-\mathrm{PHPMA}_{x}$ nanoparticles was investigated. Finally, the salt tolerance of $\mathrm{PSBMA}_{38}-\mathrm{PHPMA}_{400}$ vesicles was compared to that of PGMA $\mathrm{A}_{71}-\mathrm{PHPMA}_{400}$ vesicles; the former vesicles exhibit much better colloidal stability in the presence of $1 \mathrm{M} \mathrm{MgSO}_{4}$
\end{abstract}

\section{Introduction}

It is well known that amphiphilic AB diblock copolymers spontaneously undergo self-assembly in aqueous solution in order to minimize the unfavorable interactions between the hydrophobic blocks and the solvent. ${ }^{1}$ The resulting copolymer morphology depends on the so-called packing parameter, $p$, which is related to the relative volume fractions of the hydrophilic and hydrophobic blocks. ${ }^{2}$ A wide range of copolymer morphologies have been reported, including spherical micelles, ${ }^{3}$ worm-like particles ${ }^{4}$ and vesicles. ${ }^{5}$

Traditionally, diblock copolymer self-assembly in solution has been achieved via post-polymerization processing techniques such as thin film rehydration ${ }^{6,7}$ or a solvent switch, ${ }^{8}$ where the copolymer chains are initially dissolved in a good solvent for both blocks and then a selective solvent for one of the blocks is added in order to induce self-assembly. This approach usually involves additional purification steps to remove the non-selective solvent, e.g. by dialysis or evaporation. This self-assembly route also suffers from a major dis-

\footnotetext{
Department of Chemistry, University of Sheffield, Brook Hill, Sheffield, S3 7HF, UK. E-mail: s.p.armes@sheffield.ac.uk

$\dagger$ Electronic supplementary information (ESI) available: Additional kinetic data; ${ }^{1} \mathrm{H}$ NMR spectra for CTA, macro-CTA and diblock copolymer; TEM images of $\mathrm{S}_{38^{-}}$ $\mathrm{H}_{400}$ vesicles dispersed in pure water and in an aqueous solution of $1 \mathrm{M} \mathrm{MgSO}_{4}$; digital photographs of $\mathrm{S}_{38}-\mathrm{H}_{400}$ and $\mathrm{G}_{71}-\mathrm{H}_{400}$ vesicles in aqueous solutions containing $\mathrm{MgSO}_{4}$. See DOI: 10.1039/c5py00396b
}

advantage: it is almost invariably conducted in dilute solution (typically $<1 \% \mathrm{w} / \mathrm{w}$ copolymer).

Recently, we $\mathrm{e}^{9-13}$ and others ${ }^{14-18}$ have reported that polymerization-induced self-assembly (PISA) of various amphiphilic diblock copolymers can be readily achieved using either aqueous dispersion polymerization ${ }^{10,19}$ or aqueous emulsion polymerization $^{20-22}$ based on reversible addition-fragmentation chain transfer (RAFT) chemistry. ${ }^{23-26}$ This approach allows various copolymer morphologies to be readily prepared in situ at relatively high copolymer concentrations and requires no post-polymerization processing. One early formulation based on RAFT aqueous dispersion polymerization utilized a zwitterionic phosphobetaine homopolymer, poly(2-(methacryloyloxy)ethyl phosphorylcholine) (PMPC), as the stabilizer block and poly(2-hydroxypropyl methacrylate) (PHPMA) as the coreforming block to access a range of copolymer morphologies. ${ }^{10}$ However, the relatively high mass of the MPC repeat units meant that highly anisotropic copolymer compositions had to be targeted at relatively high copolymer solids (ca. 16-25\%) in order to access non-spherical copolymer morphologies (e.g. worms or vesicles).

Polysulfobetaines are closely related to polyphosphobetaines and both classes of polyzwitterions have been shown to be salt-responsive. ${ }^{27-35}$ The presence of salt generally leads to higher water solubility, which is sometimes known as the 'anti-polyelectrolyte' effect. ${ }^{36}$ Certain polysulfobetaines also display thermo-responsive behavior, with their upper critical solution temperature (UCST) depending on both the copolymer molecular weight and copolymer concentration. ${ }^{29,37-39}$ 
Like polyphosphobetaines, ${ }^{40-42}$ polysulfobetaines have been shown to be highly biocompatible and exhibit anti-fouling properties. $^{41,43-46}$ Importantly, polysulfobetaines are significantly cheaper than polyphosphobetaines.

In 2014 Pei and Lowe reported the synthesis of a range of diblock copolymer nano-objects comprising a polysulfobetaine stabilizer block and 2-phenylethyl methacrylate (PEMA) as the hydrophobic block. However, these copolymers were prepared via post-polymerization modification. First, a poly(2-(dimethylamino)ethyl methacrylate) (PDMA) macro-CTA was employed for the ethanolic RAFT dispersion polymerization of PEMA. ${ }^{16}$ These precursor diblock copolymers underwent self-assembly during their PISA synthesis to yield a range of copolymer morphologies, including spheres, worms and vesicles. The PDMA stabilizer block was subsequently quaternized using 1,3-propanesultone to yield polysulfobetaine-based nanoparticles. However, 1,3-propanesultone is known to be carcinogenic and the PISA synthesis was conducted in ethanol rather than water (with the purified copolymer nanoparticles being redispersed in water).

Herein we employ poly(2-(methacryloyloxy)ethyl dimethyl(3-sulfopropyl)ammonium hydroxide) (PSBMA) as a polysulfobetaine macro-CTA; this is used as a steric stabilizer to conduct the RAFT aqueous dispersion polymerization of 2-hydroxypropyl methacrylate (HPMA) in order to generate a thermo-responsive core-forming block. This formulation yields a range of PSBMA-PHPMA diblock copolymer nano-objects directly via PISA (see Fig. 1). Our approach is both versatile and efficient: it avoids post-polymerization modification with carcinogens such as 1,3-propanesultone and affords the desired nano-objects directly in water (hence subsequent transfer from ethanol to water is not required). Moreover, thermo-responsive behaviour is conferred on the resulting diblock copolymer nano-objects.

\section{Experimental}

\section{Materials}

4-Cyanopentanoic acid dithiobenzoate (CADB), [2-(methacryloyloxy)ethyl] dimethyl(3-sulfopropyl) ammonium hydroxide (SBMA) and deuterium oxide $\left(\mathrm{D}_{2} \mathrm{O}\right)$ were obtained from SigmaAldrich U.K. and were used as received. 4,4'-Azobis(4-cyanovaleric acid) (ACVA, 99\%) and 2-hydroxypropyl methacrylate (HPMA, 98\%) were obtained from Alfa Aesar (UK) and were used as received. Deuterated methanol $\left(\mathrm{CD}_{3} \mathrm{OD}\right)$ was obtained from Cambridge Isotope laboratories. Dialysis tubing was received from SpectraPor. Deionized water was used in all experiments.

\section{Methods}

Synthesis of PSBMA $_{38}$ macro-CTA. CADB RAFT agent (0.75 g, $2.7 \mathrm{mmol})$, SBMA monomer (30.0 g, $108 \mathrm{mmol})$ and ACVA (151 mg, $0.54 \mathrm{mmol}$, CTA/ACVA molar ratio $=5.0$ ) were weighed into a $500 \mathrm{ml}$ round-bottomed flask containing a stir bar. $0.5 \mathrm{M} \mathrm{NaCl}$ solution (150 g) was added and the $\mathrm{pH}$ slowly adjusted to $c a$. pH 7 using dilute aqueous $\mathrm{NaOH}$. The solution was purged with nitrogen for 45 minutes and sealed with a
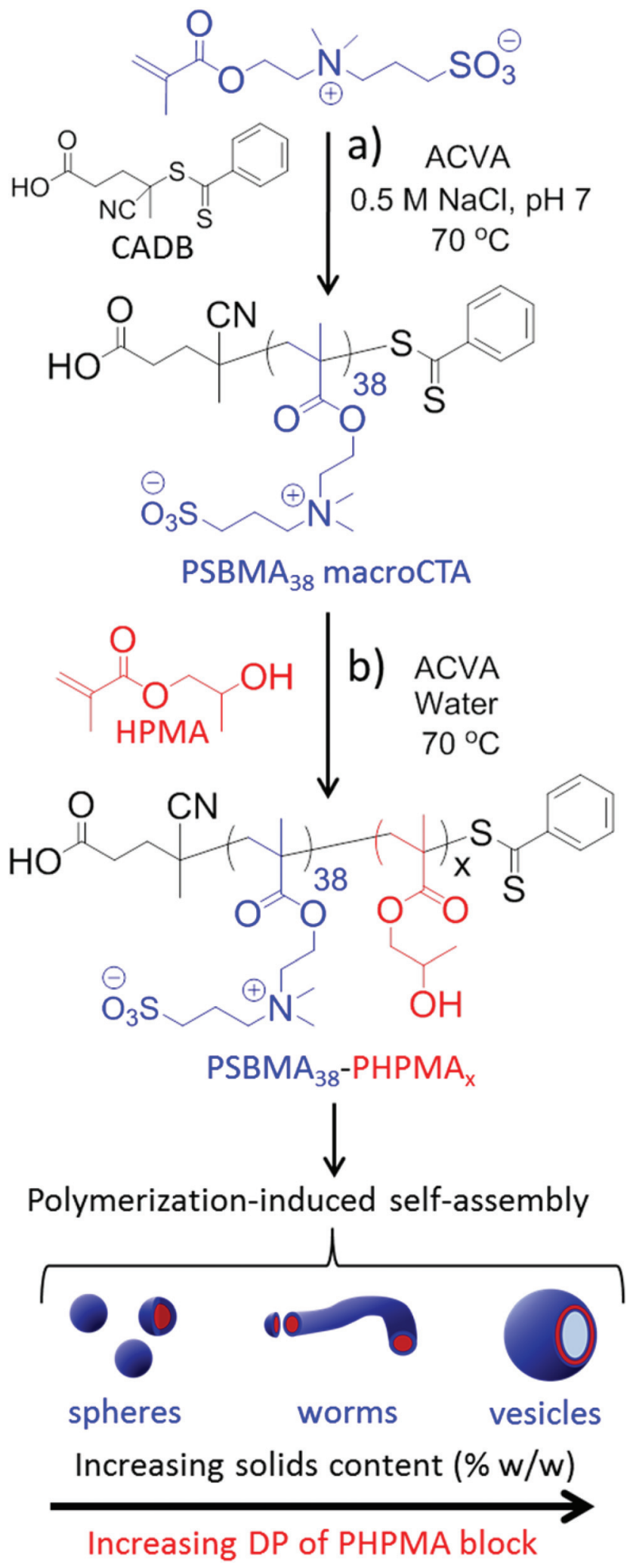

Fig. 1 (a) Synthesis of the PSBMA 38 macro-CTA via RAFT aqueous solution polymerization of SBMA. (b) RAFT aqueous dispersion polymerization of HPMA using this PSBMA 38 macro-CTA at $70{ }^{\circ} \mathrm{C}$ to afford various PSBMA-PHPMA diblock copolymer nano-objects via polymerizationinduced self-assembly (PISA). 
rubber septum under a positive nitrogen pressure. The flask was then immersed in a pre-heated oil bath set at $70{ }^{\circ} \mathrm{C}$. The polymerization was quenched after $2 \mathrm{~h}$ by rapid cooling in liquid nitrogen (final monomer conversion $=88 \%$ ). The crude PSBMA was purified by exhaustive dialysis (SpectraPor membrane, $\mathrm{MWCO}=3.5 \mathrm{kDa}$ ) against water, followed by lyophilization to yield 1 as a pink powder in $86 \%$ yield; $M_{\mathrm{n}}$ NMR $=$ $11 \mathrm{kDa}, M_{\mathrm{n} \mathrm{SEC}}=6.9 \mathrm{kDa}, M_{\mathrm{w}} / M_{\mathrm{n}}=1.09$.

Synthesis of PSBMA PB-PHPMA $_{X}$ via RAFT aqueous dispersion polymerization. A typical protocol for the synthesis of $\mathrm{PSBMA}_{47}-\mathrm{PHPMA}_{200}$ is as follows: $\mathrm{PSBMA}_{47}$ macro-CTA $(0.44 \mathrm{~g}$, $0.038 \mathrm{mmol})$, HPMA (0.82 g, $7.4 \mathrm{mmol})$, ACVA $(2.0 \mathrm{mg}$, $0.008 \mathrm{mmol}$, CTA/ACVA molar ratio $=5.0)$ and water $(4.5 \mathrm{~g})$ were weighed into a round-bottomed flask containing a stir bar. The solution was purged with nitrogen for 30 minutes and sealed with a rubber septum under a positive nitrogen pressure, prior to immersion in a pre-heated oil bath at $70{ }^{\circ} \mathrm{C}$ for $6 \mathrm{~h}$. The reaction was quenched by exposure to air and rapid cooling at $20{ }^{\circ} \mathrm{C}$. ${ }^{1} \mathrm{H}$ NMR spectroscopy analysis in $\mathrm{CD}_{3} \mathrm{OD}$ indicated less than $1 \%$ of residual HPMA monomer. For kinetic studies, aliquots were periodically removed for analysis by ${ }^{1} \mathrm{H}$ NMR spectroscopy. For brevity, the notation $\mathrm{S}_{38}-\mathrm{H}_{x}-Y$ is used where $\mathrm{S}$ stands for PSBMA, $\mathrm{H}$ for PHPMA, $x$ is the DP of the PHPMA block and $Y$ is the solids content $(\% \mathrm{w} / \mathrm{w})$ used for the copolymer synthesis.

\section{Polymer characterization}

Molecular weight distributions were assessed by aqueous gel permeation chromatography (GPC) at $40{ }^{\circ} \mathrm{C}$ using a guard column, a $5 \mu \mathrm{m}$ PL Aquagel-OH 30 column and a $5 \mu \mathrm{m}$ PL Aquagel-OH 40 column connected in series to an Agilent Technologies 1260 Infinity refractive index detector, using a phosphate buffer eluent $\left(0.08 \mathrm{M} \mathrm{Na}_{2} \mathrm{HPO}_{4}\right.$; adjusted to $\mathrm{pH} 8.9$ using $\mathrm{NaOH}$ ) at a flow rate of $1.0 \mathrm{ml} \mathrm{min}^{-1}$. The numberaverage molecular weight $\left(M_{\mathrm{n}}\right)$ and polydispersity $\left(M_{\mathrm{w}} / M_{\mathrm{n}}\right)$ were calculated using a series of near-monodisperse poly(ethylene oxide) calibration standards.

${ }^{1} \mathrm{H}$ NMR spectra were acquired using a Bruker AV1-400 MHz spectrometer in either $\mathrm{D}_{2} \mathrm{O}$ or $\mathrm{CD}_{3} \mathrm{OD}$. At least 64 scans were recorded for each sample. All chemical shifts $(\delta)$ are reported in ppm.

DLS measurements were performed using a Zetasizer NanoZS instrument (Malvern Instruments, UK) equipped with a $4 \mathrm{~mW} \mathrm{He}-\mathrm{Ne}$ laser operating at $633 \mathrm{~nm}$. Light scattering was detected at $173^{\circ}$. Hydrodynamic diameters were determined using the Stokes-Einstein equation and averaged over three consecutive runs. Copolymer dispersions were diluted to $0.2 \%$ $\mathrm{w} / \mathrm{v}$ prior to analysis at $25{ }^{\circ} \mathrm{C}$. Viscosities (and refractive indices) for aqueous solutions of $1 \mathrm{M} \mathrm{NaCl}, 2 \mathrm{M} \mathrm{NaCl}$ and $1 \mathrm{M}$ $\mathrm{MgSO}_{4}$ at $20{ }^{\circ} \mathrm{C}$ were calculated to be $1.096 \mathrm{mPa} \mathrm{s}$ (1.343), $1.219 \mathrm{mPa} s$ (1.372) and $1.884 \mathrm{mPa} \mathrm{s}$ (1.355) respectively. ${ }^{47}$

Transmission electron microscopy studies were conducted using a Phillips CM 100 TEM instrument operating at $100 \mathrm{kV}$, equipped with a Gatan 1k CCD camera. Copper/palladium TEM grids (Agar Scientific) were surfaced-coated in-house to produce a thin film of amorphous carbon. The grids were then plasma glow-discharged for 30 seconds to yield a hydrophilic surface. $10 \mu \mathrm{L}$ of the aqueous dispersion (diluted to $0.1 \% \mathrm{w} / \mathrm{w}$ ) was placed on the grid, then blotted after 1 minute to remove excess sample. The grids were then negatively stained using uranyl formate solution $(10 \mu \mathrm{L}, 0.75 \% \mathrm{w} / \mathrm{w})$ for 20 seconds, followed by blotting to remove excess staining solution and dried using a vacuum hose.

Rheology measurements were performed using an AR-G2 rheometer equipped with a variable temperature Peltier plate, a $40 \mathrm{~mL}$ aluminium cone and a solvent trap. Storage $\left(G^{\prime}\right)$ and loss $\left(G^{\prime \prime}\right)$ moduli were measured as a function of percentage strain and temperature in order to identify the linear viscoelastic region and also to determine the critical degelation temperature. Percentage strain sweeps were conducted at constant temperature $\left(37^{\circ} \mathrm{C}\right)$ using an angular frequency of 1.0 $\operatorname{rad} \mathrm{s}^{-1}$. Angular frequency sweeps were carried out at a constant applied strain of $1.0 \%$. Temperature sweeps were conducted at an angular frequency of $1.0 \mathrm{rad} \mathrm{s}^{-1}$ and an applied strain of $1.0 \%$. The temperature was increased by $2{ }^{\circ} \mathrm{C}$, with 5 minutes being allowed for thermal equilibrium between each measurement.

\section{Results and discussion}

\section{Synthesis of the PSBMA ${ }_{38}$ macro-CTA}

Synthesis of a PSBMA 38 homopolymer using 4,4'-azocyanovaleric acid (ACVA) initiator and 4-cyanopentanoic acid dithiobenzoate (CADB) as the RAFT agent was conducted in aqueous solution containing $0.50 \mathrm{M} \mathrm{NaCl}$ at $70{ }^{\circ} \mathrm{C}$. The reaction solution $\mathrm{pH}$ was adjusted to 7.2 to facilitate dissolution of the RAFT agent and electrolyte was added because it is well known that this enhances the water solubility of PSBMA. ${ }^{27,30,31}$ The polymerization kinetics for SBMA exhibited a linear semi-logarithmic plot and reached high conversion (90\%) within $3 \mathrm{~h}$ (see Fig. S1 in ESI $\dagger$ ). The $M_{\mathrm{n}}$ increased monotonically with conversion and the polydispersities remained low throughout the polymerization $\left(M_{\mathrm{w}} / M_{\mathrm{n}}<1.30\right)$. The crude PSBMA was purified by dialysis against water and recovered by lyophilization to yield macro-CTA 1 as a pink powder $\left(M_{\mathrm{n}}=5 \mathrm{kDa}, M_{\mathrm{w}} / M_{\mathrm{n}}=1.09\right.$ vs. poly(ethylene oxide) standards).

Analysis of the ${ }^{1} \mathrm{H}$ NMR spectrum of 1 recorded in $\mathrm{D}_{2} \mathrm{O}$ indicated a mean DP of 38, as calculated by comparing the integrals of the aromatic RAFT end-group signals (k, $\mathbf{n}$ and $\mathbf{m}$ ) between $7.4 \mathrm{ppm}$ and $8.0 \mathrm{ppm}$ with the polymer side-chain signals at 2.98, 3.18, 3.54, 3.78 and $4.46 \mathrm{ppm}$ (assigned as j, f, g, e and d; see Fig. 2).

\section{Polymerization-induced self-assembly}

A series of $\mathrm{PSBMA}_{38}-\mathrm{PHPMA}_{x}$ (hereafter referred to as $\mathrm{S}_{38}-\mathrm{H}_{x}$ ) diblock copolymers was prepared using this PSBMA $_{38}$ macroCTA for the RAFT aqueous dispersion polymerization of PHPMA in deionized water at $70{ }^{\circ} \mathrm{C}$. It was decided to avoid using an aqueous salt solution to enable direct comparison of the results obtained with this PISA formulation to those previously reported for the PMPC-PHPMA system. ${ }^{10}$ It is known 


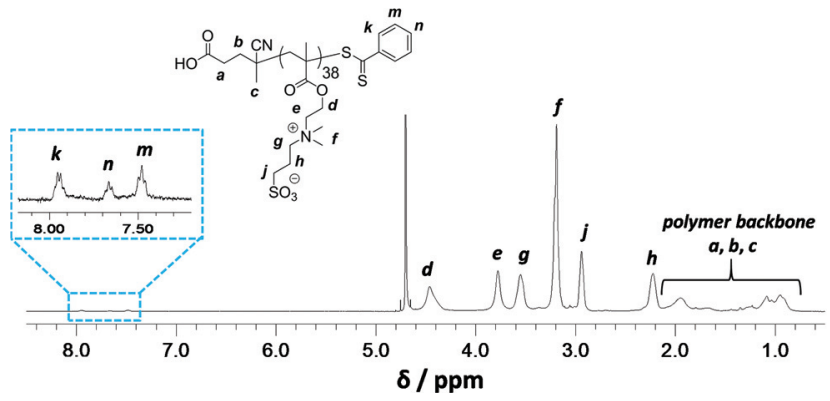

Fig. 2 Assigned ${ }^{1} \mathrm{H}$ NMR spectrum recorded for PSBMA macro-CTA 1 in $\mathrm{D}_{2} \mathrm{O}$.

that the UCST of PSBMA is reduced in the lower molecular weight limit. ${ }^{29,37,38}$ More specifically, Willcock et al. investigated the effect of chain length at a solution concentration of $1.0 \mathrm{~g} \mathrm{dm}^{-3}$ : No UCST was observed for PSBMA homopolymers with molecular weights of $20 \mathrm{kDa}(\mathrm{DP}=70)$ or below. ${ }^{39}$ Therefore, given its relatively low molecular weight and anionic carboxylate end-group (which also suppresses UCST behavior), ${ }^{48}$ the PSBMA PS $_{38}$ macro-CTA used in this work was not expected to exhibit a UCST in the absence of salt. Indeed, control experiments confirmed that a $15 \% \mathrm{w} / \mathrm{w}$ aqueous solution of $\mathrm{PSBMA}_{38}$ remained water-soluble even at $4{ }^{\circ} \mathrm{C}$ and all aqueous dispersion polymerization syntheses were performed using an initial $\mathrm{PSBMA}_{38}$ concentration of $12 \% \mathrm{w} / \mathrm{w}$ (or lower). The total solids content of the PISA formulation was varied from $10 \% \mathrm{w} / \mathrm{w}$ to $25 \% \mathrm{w} / \mathrm{w}$. High HPMA conversions were obtained within $3 \mathrm{~h}$ at $70{ }^{\circ} \mathrm{C}$. Three distinct regions can be observed in the semi-logarithmic kinetic plot (see Fig. 3).

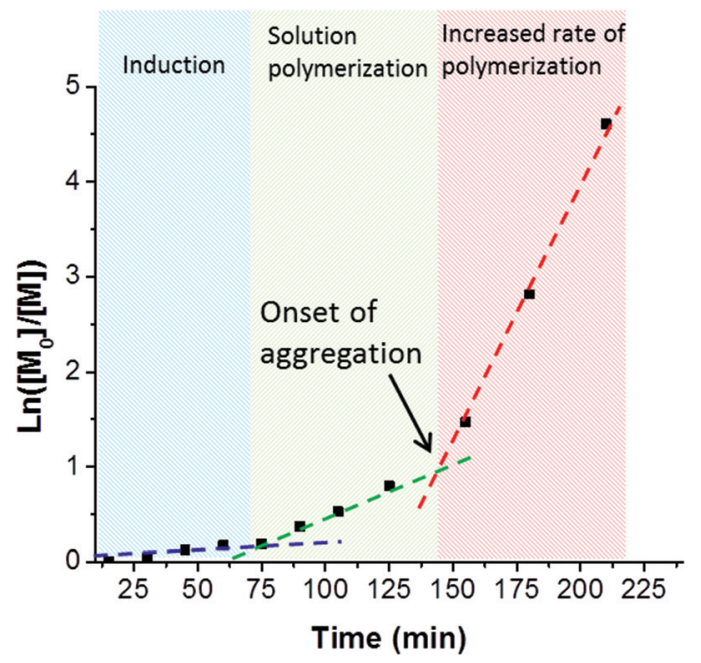

Fig. 3 First-order kinetic plot for the RAFT aqueous dispersion polymerization of HPMA conducted using a PSBMA 38 macro-CTA in deionized water at $70{ }^{\circ} \mathrm{C}$ and $20 \% \mathrm{w} / \mathrm{w}$ solids. Reaction conditions: $[$ PSBMA 38$]:[H P M A]:[A C V A]=200: 1: 0.20$. Three regimes can be identified: an induction period of approximately $75 \mathrm{~min}$, a relatively slow rate of solution polymerization up to $145 \mathrm{~min}$, and a relatively fast rate of dispersion polymerization after $145 \mathrm{~min}$. The onset of micellization aggregation occurs at 150 min, which corresponds to a HPMA conversion of $67 \%$ and equates to a mean PHPMA DP of 133.
There is an induction period for the first $75 \mathrm{~min}$, which is commonly observed for RAFT polymerizations of methacrylates conducted with dithiobenzoates, ${ }^{49,50}$ followed by a significant increase in rate for the next $70 \mathrm{~min}$ as solution polymerization occurs and water-soluble diblock copolymer chains are formed. The rate of polymerization further increases after $145 \mathrm{~min}$, since this coincides with micellar nucleation. ${ }^{51}$ At this point, the HPMA monomer becomes partitioned within the micellar core, thereby increasing the local monomer concentration and hence accounting for the enhanced rate of polymerization. ${ }^{51}$ The point at which micellar nucleation occurs corresponds to a HPMA conversion of $67 \%$ for this particular PISA formulation, which equates to a mean DP of 133 for the growing PHPMA block. This value is significantly higher than the critical degree of polymerization of 92 reported by Blanazs et al. when polymerising HPMA using a poly(glycerol methacrylate) (PGMA 47 ) macro-CTA. This difference can be rationalized by the higher molecular weight of the PSBMA $_{38}$ block $(10.9 \mathrm{kDa})$ compared to the $\mathrm{PGMA}_{47}$ block (7.5 kDa). Thus the former block occupies a larger volume fraction than the latter and, although the PSBMA $_{38}$ stabilizer block is shorter, a longer core-forming PHPMA chain is needed to induce micellization.

Systematic variation of the mean DP of the core-forming PHPMA block and the total solids content $(Y)$ enabled a detailed phase diagram to be constructed for the synthesis of $\mathrm{S}_{38}-\mathrm{H}_{x}-Y$ nanoparticles (see Fig. 4; full characterization data can be found in Table S1 in the ESI $\dagger$ ). The final copolymer compositions were determined by ${ }^{1} \mathrm{H}$ NMR analysis (see Fig. S3 in ESI $\dagger$ ). This phase diagram is rather similar to that reported by Sugihara et al. for a zwitterionic $\mathrm{PMPC}_{25}$ stabilizer block $^{10}$ and by Blanazs et al. for a PGMA $_{78}$ stabilizer block. ${ }^{11}$ In each case, the final copolymer morphology is strongly concentration-dependent, with kinetically-trapped spheres being obtained at lower solids (since the probability of spheresphere fusion is reduced under these conditions) while equilibrium vesicular morphologies are formed at higher solids. As is usually the case, ${ }^{10-13}$ the pure worm phase occupies a relatively narrow region and is bounded by mixed phases. There is also a small region corresponding to around $14-16 \% \mathrm{w} / \mathrm{w}$ solids and a PHPMA DP of 250 that contains all three copolymer phases (i.e. spheres, worms and vesicles).

TEM studies indicate a strong correlation between the mean sphere diameter $\left(D_{\text {TEM }}\right)$ and the target PHPMA block DP. Thus $D_{\text {TEM }}=34 \pm 4 \mathrm{~nm}$ for PHPMA $_{200}, D_{\text {TEM }}=42 \pm 3 \mathrm{~nm}$ for $\mathrm{PHPMA}_{300}$ and $D_{\text {TEM }}=54 \pm 6 \mathrm{~nm}$ for PHPMA 400 . TEM consistently undersizes these diblock copolymer nanoparticles relative to DLS. This is because the former technique examines dehydrated nanoparticles with collapsed stabilizer blocks, while the latter interrogates hydrated nanoparticles in aqueous solution. In addition, TEM reports a number-average diameter whereas DLS reports a $z$-average diameter, which is inherently biased towards larger nanoparticles. If $\mathrm{S}_{38}-\mathrm{H}_{400}$ nanoparticles are prepared at higher solids contents $(12.5 \% \mathrm{w} / \mathrm{w})$, then the DLS diameter increases up to $111 \mathrm{~nm}$ (polydispersity $=0.05$ ). Along with the greater turbidity of the dispersion, this suggests 


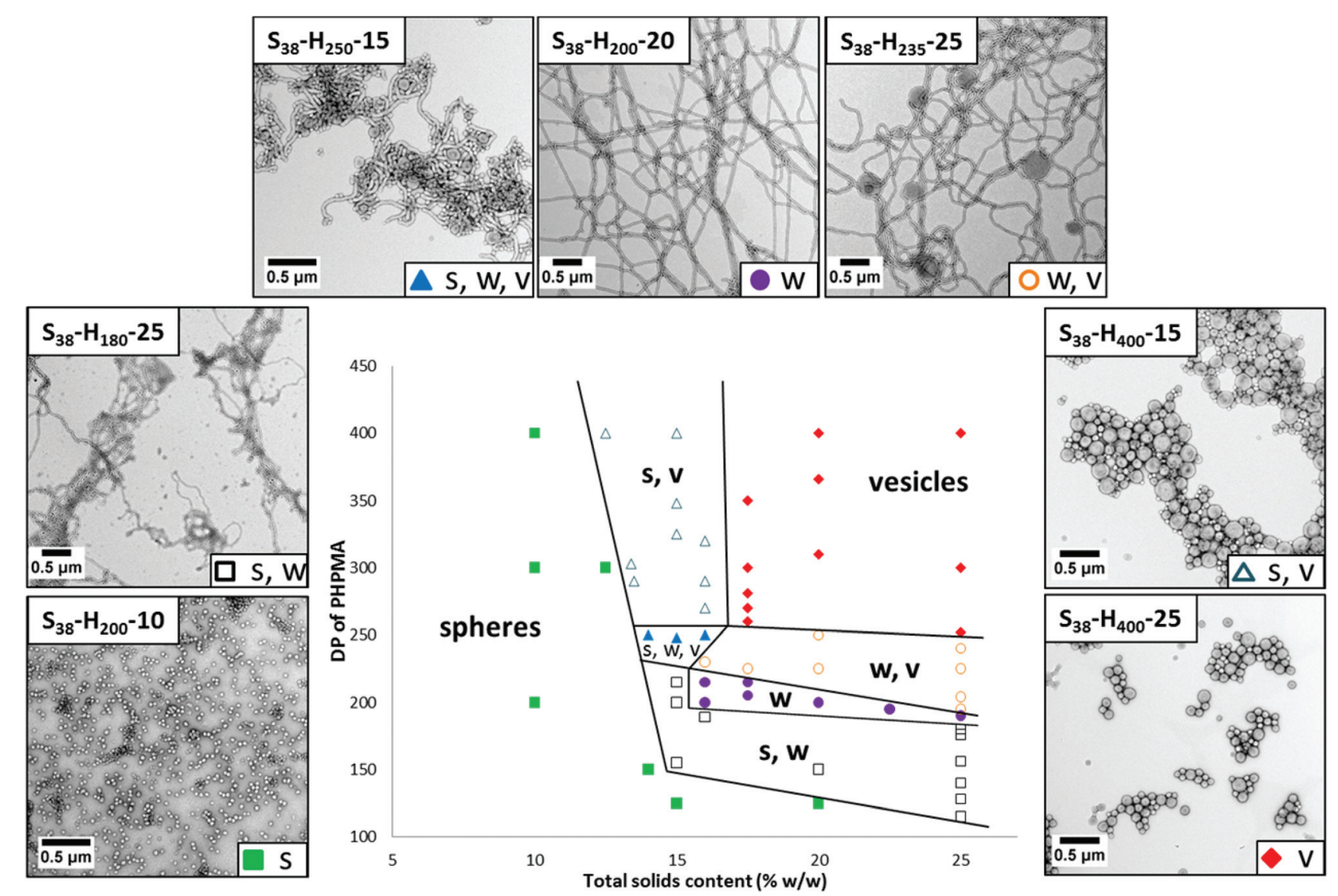

Fig. 4 Detailed phase diagram constructed for the preparation of $\mathrm{S}_{38}-\mathrm{H}_{x}-Y$ diblock copolymer nano-objects by RAFT aqueous dispersion polymerization of HPMA at $70{ }^{\circ} \mathrm{C}$ (for brevity, $\mathrm{S}$ denotes PSBMA and $\mathrm{H}$ denotes PHPMA). The target DP of the PHPMA block ( $x$ ) and the total solids content $(Y)$ were systematically varied and the diblock copolymer morphologies were assigned by post mortem TEM analysis of the final copolymer dispersions after appropriate dilution. Also shown are representative TEM images obtained for the various phases; $\mathbf{S}$ denotes spheres, $\mathbf{W}$ denotes worms and $\mathrm{V}$ denotes vesicles.

the presence of larger particles. TEM analysis indicates two distinct populations, corresponding to spheres $\left(D_{\text {TEM }}=57 \pm\right.$ $6 \mathrm{~nm})$ and relatively well-defined vesicle $\left(D_{\text {TEM }}=97 \pm 7 \mathrm{~nm}\right)$. The vesicles dimensions observed by TEM correlate quite well with those indicated by DLS. However, the latter technique is insensitive to spheres as the light scattering is dominated by the larger vesicles. Increasing the total solids concentration to $20 \% \mathrm{w} / \mathrm{w}$ for the synthesis of $\mathrm{S}_{38}-\mathrm{H}_{400}$ nanoparticles produces a pure vesicle phase $\left(D_{\text {TEM }}=98 \pm 13 \mathrm{~nm}\right)$, as indicated by TEM analysis, with DLS studies reporting a $z$-average diameter of $114 \mathrm{~nm}$ (polydispersity $=0.04$ ). Thus the mean size of the pure vesicles is comparable to that of the vesicle population within the spheres plus vesicles mixed phase (Fig. 5 and 6).

Varying the target DP of the PHPMA block at a fixed total solids concentration of $20 \% \mathrm{w} / \mathrm{w}$ allows access to pure spheres, worms and vesicles, as well as various mixed phases comprising these two or more morphologies (see Fig. 7). For example, targeting $\mathrm{S}_{38}-\mathrm{H}_{125}$ leads to ill-defined spheres (TEM indicates $D_{\text {TEM }}=27 \pm 5 \mathrm{~nm}$; DLS reports a $z$-average diameter of $34 \mathrm{~nm}$ (polydispersity $=0.14)$ ). Increasing the target DP of the PHPMA block to 150 produces a mixed phase of spheres and worms, as indicated by TEM analysis. Visual inspection of this dispersion confirms an increase in turbidity and formation of a free-standing gel. Targeting a PHPMA block DP of 200 results in the formation of a pure worm phase.

Both $\mathrm{S}_{38}-\mathrm{H}_{225}$ and $\mathrm{S}_{38}-\mathrm{H}_{250}$ formulations produced a mixed phase comprising worms and vesicles, with a higher proportion of vesicles being observed in the latter case as estimated by TEM analysis. The visual appearance and macroscopic behavior of these two dispersions were consistent with these TEM observations. $\mathrm{S}_{38}-\mathrm{H}_{225}$ formed an opaque freestanding gel, while $\mathrm{S}_{38}-\mathrm{H}_{250}$ comprised an opaque viscous solution. A pure vesicle phase was obtained when targeting a PHPMA block DP of 310 or higher. TEM studies indicate the formation of relatively polydisperse vesicles ranging from approximately $90 \mathrm{~nm}$ to $520 \mathrm{~nm}\left(D_{\text {TEM }}=214 \pm 122 \mathrm{~nm}\right)$, which correspond quite well to the $z$-average diameter of $202 \mathrm{~nm}$ reported by DLS analysis.

\section{Thermo-responsive behavior of $\mathrm{S}_{38}-\mathrm{H}_{x}-Y$ dispersions}

There is considerable literature precedent for thermo-responsive PHPMA-based nano-objects in aqueous solution. ${ }^{12,13,52,53}$ 

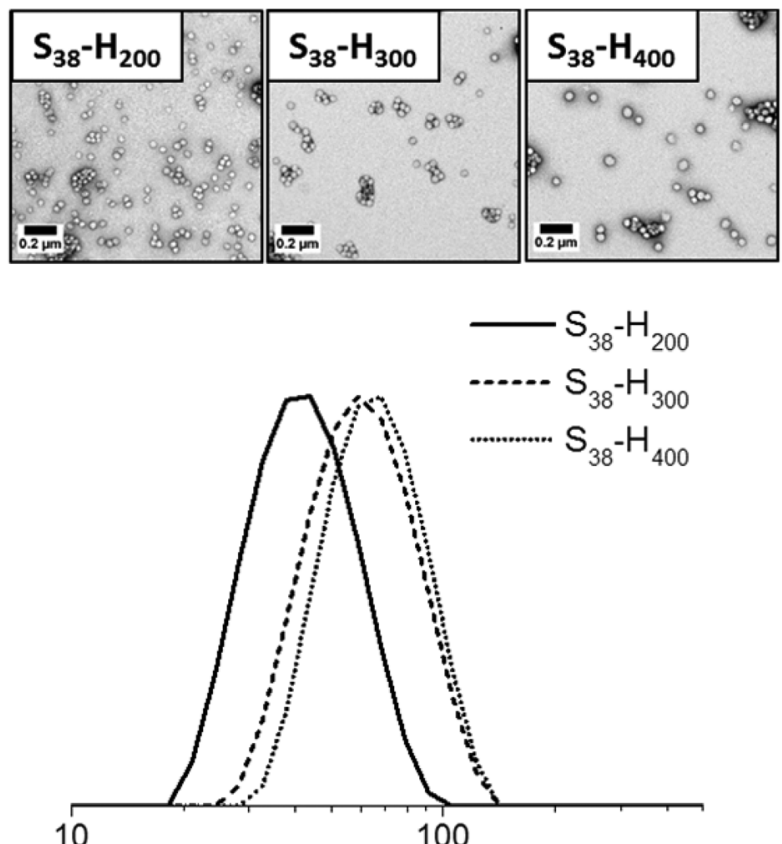

Z-average diameter ( $\mathrm{nm}$ )

Fig. 5 TEM images and corresponding DLS particle size distributions obtained for spherical $\mathrm{S}_{38}-\mathrm{H}_{x}-10$ nanoparticles when $x=200,300$ or 400.

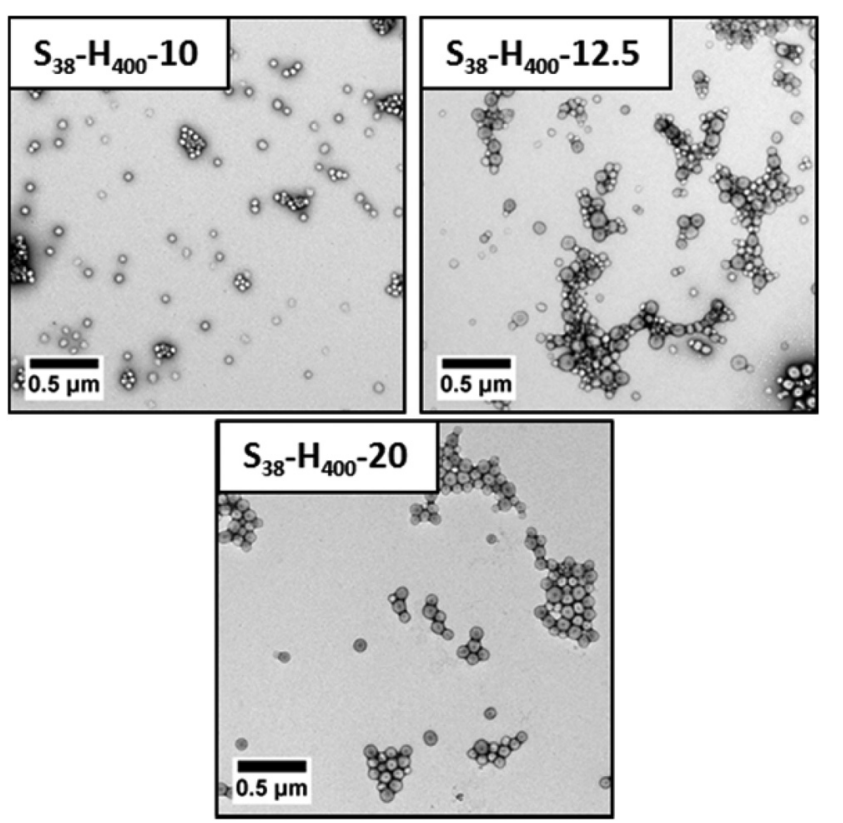

Fig. 6 Representative TEM images obtained for $\mathrm{PSBMA}_{38}-\mathrm{PHPMA}_{400}$ nanoparticles prepared at various solids contents. The copolymer morphology evolves from kinetically-trapped spheres $(10 \% \mathrm{w} / \mathrm{w})$ to equilibrium vesicles $(20 \% \mathrm{w} / \mathrm{w})$ via a spheres plus vesicles mixed phase $(12.5 \%$ $w / w)$.
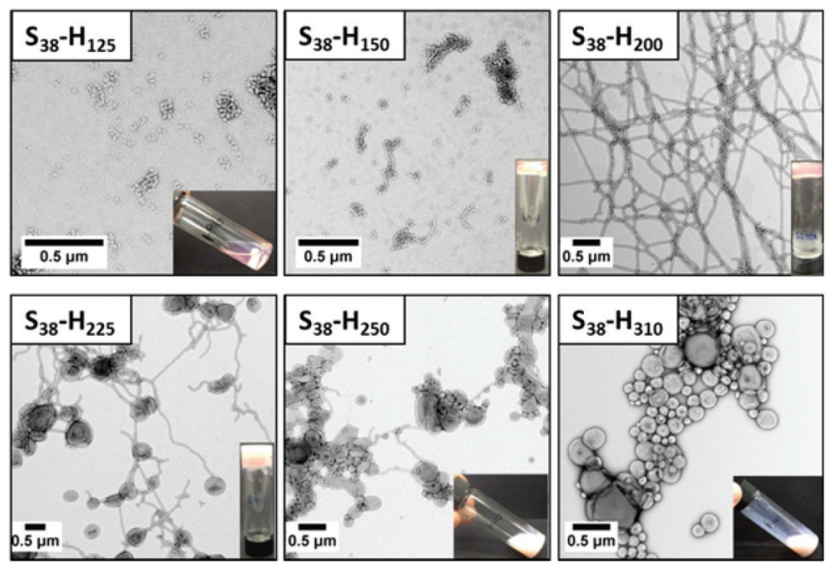

Fig. 7 Representative TEM images obtained for PSBMA $_{38}-$ PHPMA $_{x}$ (denoted as $\mathrm{S}_{38}-\mathrm{H}_{x}-20$ for brevity) nano-objects prepared by RAFT aqueous dispersion polymerization of HPMA at $70{ }^{\circ} \mathrm{C}$ at a total solids concentration of $20 \% \mathrm{w} / \mathrm{w}$. A digital photograph of the physical appearance of each copolymer dispersion is shown as an inset in each TEM image. The scale bar in each case is $0.5 \mu \mathrm{m}$. The tube inversion test confirms the formation of free-standing gels in three cases, whereas the other three dispersions remained free-flowing.

Hence the thermo-responsive behavior of selected $\mathrm{S}_{38}-\mathrm{H}_{x}-Y$ dispersions were investigated using variable temperature oscillatory rheology. For example, a $\mathrm{S}_{38}-\mathrm{H}_{200}-10$ dispersion formed a rather soft worm gel $\left(G^{\prime} \sim 15 \mathrm{~Pa}\right)$ at $20{ }^{\circ} \mathrm{C}$. A temperature sweep from $37^{\circ} \mathrm{C}$ to $2{ }^{\circ} \mathrm{C}$ led to an increase in gel strength up to approximately $40 \mathrm{~Pa}$, which is consistent with previous observations made by Warren et $a .^{13}$ It is suggested that the initially short worms become longer upon cooling, hence a larger number of inter-worm contacts leads to a higher gel strength. $G^{\prime \prime}$ exceeded $G^{\prime}$ at around $2{ }^{\circ} \mathrm{C}$, indicating degelation.

This is a result of greater solvation of the PHPMA core, which lowers the packing parameter $^{1}$ and results in a morphology transition from a worm gel to free-flowing spheres. ${ }^{52,53}$ However, this thermal transition proved to be irreversible, since $G^{\prime \prime}$ remained greater than $G^{\prime}$ throughout the subsequent heating cycle (see Fig. 8A). This thermo-responsive behavior is in contrast to that reported for PGMA $_{54}-\mathrm{PHPMA}_{140}$ worm gels, ${ }^{52}$ but is similar to that observed by Warren et al. for a PEG $_{113}-\mathrm{PHPMA}_{220}$ worm gel. ${ }^{13}$ During such thermal cycling, the temperature was lowered by $2{ }^{\circ} \mathrm{C}$ for each measurement, with 5 min being allowed between each data point to ensure thermal equilibrium. The time required to induce degelation at a given copolymer concentration was also examined. The same $\mathrm{S}_{38}-\mathrm{H}_{200}-10$ worm gel was held at $2{ }^{\circ} \mathrm{C}$ for $200 \mathrm{~min}$ (see Fig. 8B). For the first $60 \mathrm{~min}$, the worm gel remained intact since $G^{\prime}$ exceeded $G^{\prime \prime}$ (and $G^{\prime} \sim 65 \mathrm{~Pa}$ ). However, $G^{\prime \prime}$ became greater than $G^{\prime}$ after $60 \mathrm{~min}$, producing a free-flowing liquid. Degelation was confirmed by visual inspection. TEM studies were undertaken, both for the original worm gel at $20^{\circ} \mathrm{C}$ and also $2 \mathrm{~h}$ after this dispersion was held at $2^{\circ} \mathrm{C}$. There was a dramatic change in copolymer morphology from worms to spheres, which accounts for the observation of degelation. 

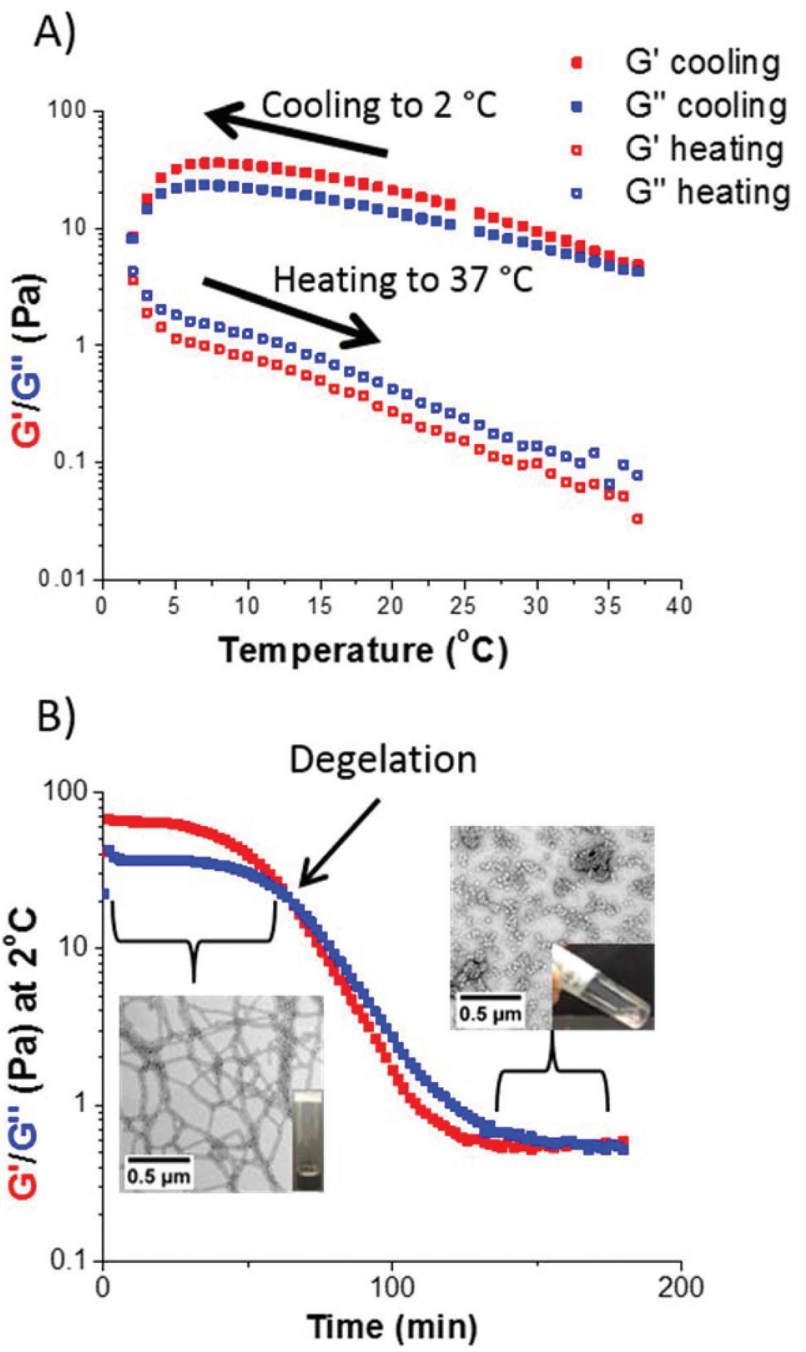

Fig. 8 (A) Storage $\left(G^{\prime}\right)$ and loss $\left(G^{\prime \prime}\right)$ moduli recorded for a $10 \% \mathrm{w} / \mathrm{w}$ $\mathrm{S}_{38}-\mathrm{H}_{200}$ worm gel upon cooling from $37^{\circ} \mathrm{C}$ to $2{ }^{\circ} \mathrm{C}$ followed by heating up to $37^{\circ} \mathrm{C}$. Irreversible degelation occurred at $2{ }^{\circ} \mathrm{C}$. (B) Storage $\left(G^{\prime}\right)$ and loss $\left(G^{\prime \prime}\right)$ moduli recorded for a $10 \% \mathrm{w} / \mathrm{w} \mathrm{S}_{38}-\mathrm{H}_{200}$ worm gel held at $2{ }^{\circ} \mathrm{C}$ for $200 \mathrm{~min}$. Degelation occurred after $60 \mathrm{~min}$ at this temperature to produce a free-flowing liquid. TEM images recorded before cooling and $2 \mathrm{~h}$ after being held at $2{ }^{\circ} \mathrm{C}$ confirmed a worm-to-sphere transition. Both sets of measurements were conducted at $1.0 \%$ applied strain using an angular frequency of $1.0 \mathrm{rad} \mathrm{s}^{-1}$.

DLS studies of the diluted copolymer dispersions were also consistent with these TEM observations: the $z$-average diameter of the original worms at $20{ }^{\circ} \mathrm{C}$ was $420 \mathrm{~nm}$ (polydispersity $=0.29$ ), whereas the $z$-average diameter was reduced to $30 \mathrm{~nm}$ (polydispersity $=0.25$ ) after cooling to $2^{\circ} \mathrm{C}$ for $2 \mathrm{~h}$. The latter dimensions suggest the formation of polydisperse spheres.

A dispersion of $\mathrm{S}_{38}-\mathrm{H}_{310}-25$ vesicles was cooled to $4{ }^{\circ} \mathrm{C}$ for $48 \mathrm{~h}$. The original dispersion was an opaque viscous liquid at $20{ }^{\circ} \mathrm{C}$. Visual inspection of the cold dispersion at $4{ }^{\circ} \mathrm{C}$ confirmed the formation of a turbid gel, as demonstrated by the tube inversion test. TEM studies indicated that the initial vesicles had transformed into a mixed phase comprising worms and vesicles (see Fig. 9).
Formation of the worm population accounts for the observation of macroscopic gelation. This dispersion did not undergo degelation on warming to room temperature, even on a time scale of several weeks. However, heating to $70{ }^{\circ} \mathrm{C}$ for 5 hours resulted in degelation. TEM studies indicated the presence of mainly vesicles, but some short worms are also observed. These short worms persist even after heating at $70{ }^{\circ} \mathrm{C}$ for $16 \mathrm{~h}$.

Therefore this transition cannot be considered to be fully reversible. Again, this behavior is similar to that of the $\mathrm{PEG}_{113^{-}}$ PHPMA $_{220}$ worms reported by Warren et al. ${ }^{13}$

The above examples suggest that $\mathrm{S}_{38}-\mathrm{H}_{x}$ nano-objects can be transformed into lower-order morphologies upon cooling. This indicates a reduction in the packing parameter under these conditions, which is consistent with a higher degree of plasticization of the PHPMA core-forming block. However, it appears that this thermo-responsive behavior is not fully reversible. This aspect is not yet understood and warrants further studies.

\section{Behavior of $S_{38}-H_{x}$ nano-objects in the presence of added electrolyte}

As previously discussed, polysulfobetaines such as PSBMA are known to exhibit enhanced aqueous solubility in the presence of salt compared to pure water. ${ }^{27,30,31}$ Therefore the tolerance of PSBMA-stabilized vesicles towards the addition of electrolyte was investigated. $\mathrm{S}_{38}-\mathrm{H}_{400}-25$ vesicles were diluted to $0.02 \% \mathrm{w} / \mathrm{v}$ using either water or various salt solutions and their colloidal stabilities were compared to that of PGMA $_{71}-\mathrm{PHPMA}_{400}-20$ (denoted $\mathrm{G}_{71}-\mathrm{H}_{400}-20$ ) vesicles. Each aqueous dispersion was analyzed by DLS immediately after dilution, again after $24 \mathrm{~h}$ and finally after ageing for one week at $20^{\circ} \mathrm{C}$. In such experiments, any apparent increase in size is taken to be evidence of particle aggregation caused by colloidal destabilization. The results are summarized in Table 1 (see overleaf).

$\mathrm{S}_{38}-\mathrm{H}_{400}-25$ vesicles remained stable in either $1 \mathrm{M}$ or $2 \mathrm{M}$ $\mathrm{NaCl}$ solution. In $1 \mathrm{M} \mathrm{MgSO}_{4}$ solution, the vesicles actually appear smaller compared to that observed in water $(119 \mathrm{~nm} v s$. $140 \mathrm{~nm}$ ). TEM studies confirmed that no discernible change in copolymer morphology occurred under these conditions (see Fig. S4 in ESI $\dagger$ ). A possible explanation for these DLS observations is that the PSBMA chains expressed at the outer leaflet of the vesicles become less hydrated in the presence of $1 \mathrm{M}$ $\mathrm{MgSO}_{4}$, which in turn reduces the mean hydrodynamic diameter of the vesicles. In contrast, exposure to $2 \mathrm{M} \mathrm{MgSO}_{4}$ solution results in macroscopic precipitation of the $\mathrm{S}_{38}-\mathrm{H}_{400}$ vesicles (see Fig. S5 in ESI†). This is commonly known as the "salting out" effect. Dissolution of this $2: 2$ electrolyte produces a significantly higher ionic strength than 1:1 electrolytes such as $\mathrm{NaCl}$, which explains why the $\mathrm{S}_{38}-\mathrm{H}_{400}$ vesicles remain colloidally stable in $2 \mathrm{M} \mathrm{NaCl}$, but become aggregated in the presence of $2 \mathrm{M} \mathrm{MgSO}_{4}$.

As a comparison, $\mathrm{G}_{71}-\mathrm{H}_{400}-20$ vesicles were also exposed to various salt solutions. These vesicles also exhibited reasonable colloidal stability in either $1 \mathrm{M}$ or $2 \mathrm{M} \mathrm{NaCl}$ for at least a week (see Table 1), although a small degree of aggregation can be detected in the particle size distributions obtained by DLS (see 


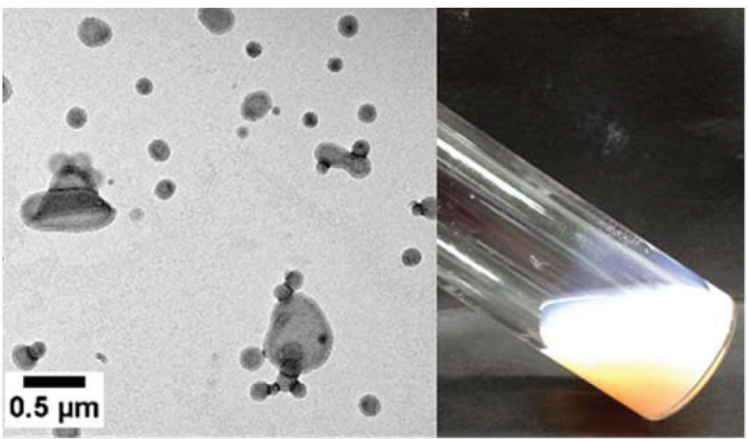

\section{$4{ }^{\circ} \mathrm{C} \downarrow 48 \mathrm{hr}$}
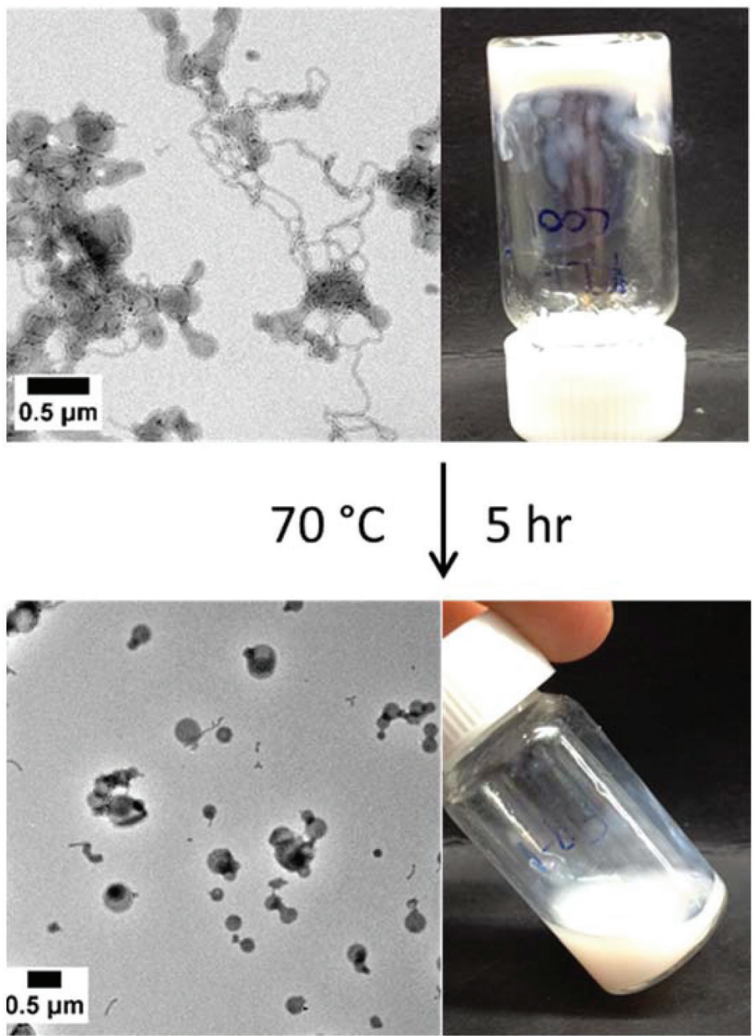

Fig. 9 TEM images and physical state of the dispersions obtained for (top) $\mathrm{S}_{38}-\mathrm{H}_{310}-25$ vesicles at $20^{\circ} \mathrm{C}$ and (middle) a mixed phase of worms and vesicles formed after being held at $4{ }^{\circ} \mathrm{C}$ for $48 \mathrm{~h}$ and (bottom) a mixed phase of vesicles and short worms obtained after heating to $70{ }^{\circ} \mathrm{C}$ for 5 hours.

Fig. 10). However, unlike the $\mathrm{S}_{38}-\mathrm{H}_{400}$ spheres and vesicles, the $\mathrm{G}_{71}-\mathrm{H}_{400}$ vesicles proved to be unstable with respect to particle aggregation in the presence of $1 \mathrm{M} \mathrm{MgSO}_{4}$, with immediate macroscopic precipitation being observed under these conditions (see Fig. S5 in the ESI $\dagger$ ). In summary, these 'added salt' studies indicate that the zwitterionic PSBMA $_{38}$ block is a somewhat more salt-tolerant steric stabilizer than the nonionic PGMA $_{71}$ block under the same conditions, which is consistent with earlier literature reports. ${ }^{27,37,54-56}$
Table 1 Summary of $z$-average DLS diameters obtained for PSBMA S8stabilized vesicles and PGMA ${ }_{71}$-stabilized vesicles at $20{ }^{\circ} \mathrm{C}$ in the presence of either water or added salt

\begin{tabular}{llll}
\hline $\begin{array}{l}\text { Nanoparticle } \\
\text { type }\end{array}$ & $\begin{array}{l}\text { Aqueous } \\
\text { solution }\end{array}$ & $\begin{array}{l}\text { Initial DLS } \\
\text { diameter/nm } \\
(\mathrm{PDI})\end{array}$ & $\begin{array}{l}\text { DLS diameter after } \\
\text { one week/nm } \\
(\mathrm{PDI})\end{array}$ \\
\hline $\mathrm{S}_{38}-\mathrm{H}_{400}-25$ vesicles & $\begin{array}{l}\text { Water } \\
1 \mathrm{M} \mathrm{NaCl}\end{array}$ & $140(0.03)$ & $140(0.03)$ \\
& $2 \mathrm{M} \mathrm{NaCl}$ & $140(0.04)$ & $141(0.03)$ \\
& $1 \mathrm{M} \mathrm{MgSO} 4$ & $119(0.05)$ & $118(0.09)$ \\
$\mathrm{G}_{71}-\mathrm{H}_{400}-20$ vesicles & $\mathrm{Water}$ & $314(0.14)$ & $315(0.12)$ \\
& $1 \mathrm{M} \mathrm{NaCl}$ & $307(0.19)$ & $310(0.22)$ \\
& $2 \mathrm{M} \mathrm{NaCl}$ & $314(0.19)$ & $312(0.15)$ \\
& $1 \mathrm{M} \mathrm{MgSO} 4$ & Precipitate & - \\
& & &
\end{tabular}

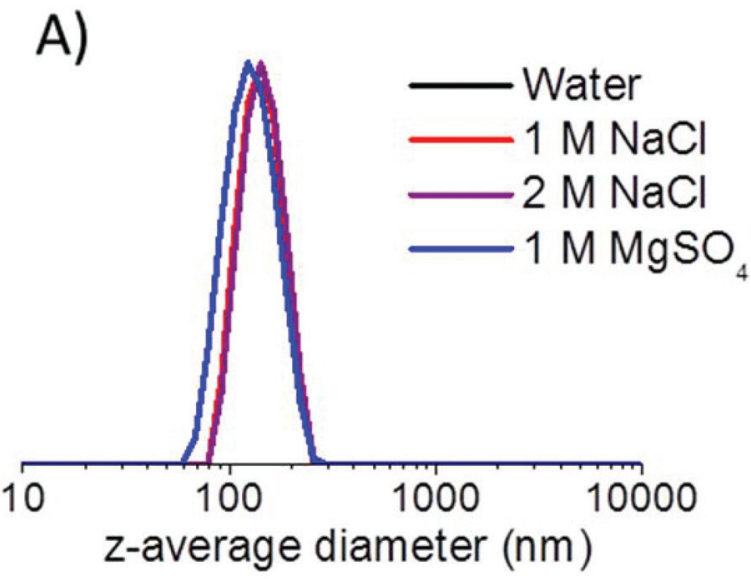

B)

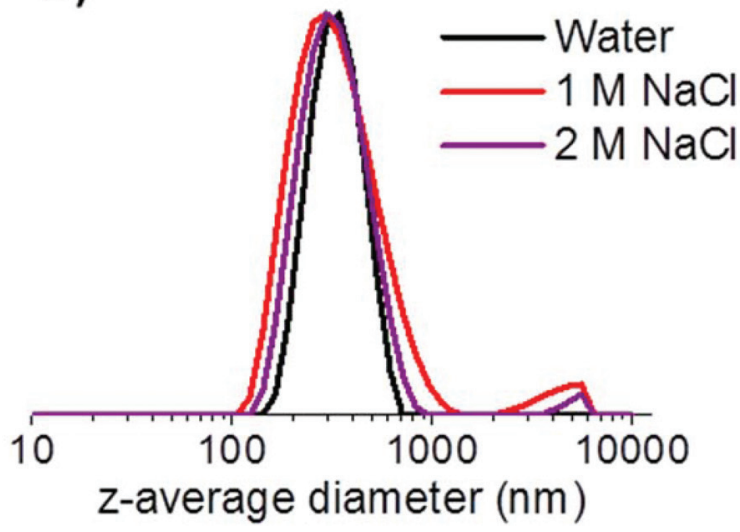

Fig. 10 Intensity-average particle size distributions obtained by DLS for (a) $\mathrm{S}_{38}-\mathrm{H}_{400}$ vesicles and (b) $\mathrm{G}_{71}-\mathrm{H}_{400}$ vesicles after being aged in various aqueous salt solutions for one week.

\section{Conclusions}

A near-monodisperse polysulfobetaine macro-CTA with a mean DP of 38 has been utilized as the water-soluble stabilizer block for the RAFT aqueous dispersion polymerization of HPMA to produce a range of copolymer morphologies via polymerization-induced self-assembly (PISA). Systematic variation of the 
mean DP of the structure-directing hydrophobic PHPMA block and the copolymer concentration enables pure spheres, worms or vesicles to be obtained. However, construction of a detailed phase diagram is required for reproducible targeting of pure worms, since this anisotropic morphology occupies rather narrow phase space. Degelation of a $\mathrm{S}_{38}-\mathrm{H}_{200}$ worm gel occurs on cooling: this thermal transition is irreversible as judged by both the tube inversion test and temperature-dependent oscillatory rheology studies. TEM images recorded for dried diluted aqueous dispersions prepared before and after cooling suggests that degelation is the result of a worm-to-sphere transition. In addition, a pure vesicle phase undergoes a sol-gel transition upon cooling as a result of formation of a mixed phase comprising worms and vesicles. Finally, the colloidal stability of $\mathrm{S}_{38}-\mathrm{H}_{400}$ vesicles in the presence of added salt was compared to that of a control sample of $\mathrm{G}_{71}-\mathrm{H}_{400}$ vesicles. The $\mathrm{S}_{38}-\mathrm{H}_{400}$ vesicles remained stable with respect to aggregation in the presence of $1 \mathrm{M} \mathrm{MgSO}_{4}$, whereas $\mathrm{G}_{71}-\mathrm{H}_{400}$ vesicles underwent macroscopic precipitation under the same conditions. Thus, the zwitterionic PSBMA stabilizer confers significantly higher salt tolerance than a non-ionic poly(glycerol monomethacrylate) stabilizer.

\section{Acknowledgements}

SPA acknowledges the European Research Council for a fiveyear ERC Advanced Investigator grant (PISA 320372) which provided post-doctoral support for KD. EPSRC is also thanked for a Platform grant (EP/J007846/1) to support NJW. Rheanna Perry is acknowledged for providing the PGMA 1 - PHPMA $_{400}$ vesicles.

\section{Notes and references}

1 A. Blanazs, S. P. Armes and A. J. Ryan, Macromol. Rapid Commun., 2009, 30, 267-277.

2 J. Israelachvili, Intermolecular and Surface Forces, Academic Press, London, 2nd edn, 1991.

3 G. Riess, Prog. Polym. Sci., 2003, 28, 1107-1170.

4 L. Zhang and A. Eisenberg, Science, 1995, 268, 1728-1731.

5 D. E. Discher and A. Eisenberg, Science, 2002, 297, 967-973.

6 K. Kita-Tokarczyk, J. Grumelard, T. Haefele and W. Meier, Polymer, 2005, 46, 3540-3563.

7 J. Du and R. K. O'Reilly, Soft Matter, 2009, 5, 3544-3561.

8 L. Zhang and A. Eisenberg, J. Am. Chem. Soc., 1996, 118, 3168-3181.

9 Y. Li and S. P. Armes, Angew. Chem., Int. Ed., 2010, 49, 4042-4046.

10 S. Sugihara, A. Blanazs, S. P. Armes, A. J. Ryan and A. L. Lewis, J. Am. Chem. Soc., 2011, 133, 15707-15713.

11 A. Blanazs, A. J. Ryan and S. P. Armes, Macromolecules, 2012, 45, 5099-5107.

12 V. Ladmiral, M. Semsarilar, I. Canton and S. P. Armes, J. Am. Chem. Soc., 2013, 135, 13574-13581.
13 N. J. Warren, O. O. Mykhaylyk, D. Mahmood, A. J. Ryan and S. P. Armes, J. Am. Chem. Soc., 2013, 136, 1023-1033.

14 Z. An, Q. Shi, W. Tang, C.-K. Tsung, C. J. Hawker and G. D. Stucky, J. Am. Chem. Soc., 2007, 129, 14493-14499.

15 G. Delaittre, M. Save and B. Charleux, Macromol. Rapid Commun., 2007, 28, 1528-1533.

16 Y. Pei and A. B. Lowe, Polym. Chem., 2014, 5, 2342-2351.

17 C. A. Figg, A. Simula, K. A. Gebre, B. S. Tucker, D. M. Haddleton and B. S. Sumerlin, Chem. Sci., 2015, 6, 1230-1236.

18 J. Rieger, C. Grazon, B. Charleux, D. Alaimo and C. Jérôme, J. Polym. Sci., Part A: Polym. Chem., 2009, 47, 2373-2390.

19 N. J. Warren and S. P. Armes, J. Am. Chem. Soc., 2014, 136, 10174-10185.

20 J. Rieger, F. Stoffelbach, C. Bui, D. Alaimo, C. Jérôme and B. Charleux, Macromolecules, 2008, 41, 4065-4068.

21 V. J. Cunningham, A. M. Alswieleh, K. L. Thompson, M. Williams, G. J. Leggett, S. P. Armes and O. M. Musa, Macromolecules, 2014, 47, 5613-5623.

22 J. Rieger, G. Osterwinter, C. Bui, F. Stoffelbach and B. Charleux, Macromolecules, 2009, 42, 5518-5525.

23 J. Chiefari, Y. Chong, F. Ercole, J. Krstina, J. Jeffery, T. Le, R. Mayadunne, G. Meijs, C. Moad and G. Moad, Macromolecules, 1998, 31, 5559-5562.

24 G. Moad, E. Rizzardo and S. H. Thang, Aust. J. Chem., 2005, 58, 379-410.

25 G. Moad, E. Rizzardo and S. H. Thang, Aust. J. Chem., 2012, 65, 985-1076.

26 D. J. Keddie, Chem. Soc. Rev., 2014, 43, 496-505.

27 A. B. Lowe, N. C. Billingham and S. P. Armes, Macromolecules, 1999, 32, 2141-2148.

28 A. B. Lowe and C. L. McCormick, Chem. Rev., 2002, 102, 4177-4190.

29 Y. J. Che, Y. Tan, J. Cao and G. Y. Xu, J. Macromol. Sci., Phys., 2010, 49, 695-710.

30 P. Mary, D. D. Bendejacq, M. P. Labeau and P. Dupuis, J. Phys. Chem. B, 2007, 111, 7767-7777.

31 J. C. Salamone, W. Volksen, A. P. Olson and S. C. Israel, Polymer, 1978, 19, 1157-1162.

32 J. Virtanen, M. Arotçaréna, B. Heise, S. Ishaya, A. Laschewsky and H. Tenhu, Langmuir, 2002, 18, 5360-5365.

33 D. Wang, T. Wu, X. Wan, X. Wang and S. Liu, Langmuir, 2007, 23, 11866-11874.

34 M. Kobayashi, Y. Terayama, M. Kikuchi and A. Takahara, Soft Matter, 2013, 9, 5138-5148.

$35 \mathrm{~J}$. Rodríguez-Hernández and $\mathrm{S}$. Lecommandoux, J. Am. Chem. Soc., 2005, 127, 2026-2027.

36 W. Schärtl, Light Scattering from Polymer Solutions and Nanoparticle Dispersions, Springer-Verlag, Berlin Heidelberg, Berlin, 2007.

37 D. N. Schulz, D. G. Peiffer, P. K. Agarwal, J. Larabee, J. J. Kaladas, L. Soni, B. Handwerker and R. T. Garner, Polymer, 1986, 27, 1734-1742.

38 Z. Dong, J. Mao, D. Wang, M. Yang, W. Wang, S. Bo and X. Ji, Macromol. Chem. Phys., 2014, 215, 111-120.

39 H. Willcock, A. Lu, C. F. Hansell, E. Chapman, I. R. Collins and R. K. O'Reilly, Polym. Chem., 2014, 5, 1023-1030. 
40 J. Du, Y. Tang, A. L. Lewis and S. P. Armes, J. Am. Chem. Soc., 2005, 127, 17982-17983.

41 S. L. West, J. P. Salvage, E. J. Lobb, S. P. Armes, N. C. Billingham, A. L. Lewis, G. W. Hanlon and A. W. Lloyd, Biomaterials, 2004, 25, 1195-1204.

42 J. P. Salvage, S. F. Rose, G. J. Phillips, G. W. Hanlon, A. W. Lloyd, I. Y. Ma, S. P. Armes, N. C. Billingham and A. L. Lewis, J. Controlled Release, 2005, 104, 259-270.

43 Y. J. Shih, Y. Chang, A. Deratani and D. Quemener, Biomacromolecules, 2012, 13, 2849-2858.

44 Y. J. Shih and Y. Chang, Langmuir, 2010, 26, 17286-17294.

45 Y. Chang, W. Y. Chen, W. Yandi, Y. J. Shih, W. L. Chu, Y. L. Liu, C. W. Chu, R. C. Ruaan and A. Higuchi, Biomacromolecules, 2009, 10, 2092-2100.

46 Y. Chang, S. C. Liao, A. Higuchi, R. C. Ruaan, C. W. Chu and W. Y. Chen, Langmuir, 2008, 24, 5453-5458.

47 F. Lee Rodkey, Clin. Chem., 1966, 12, 517-518.

48 F. Liu, J. Seuring and S. Agarwal, J. Polym. Sci., Part A: Polym. Chem., 2012, 50, 4920-4928.
49 C. Barner-Kowollik, M. Buback, B. Charleux, M. L. Coote, M. Drache, T. Fukuda, A. Goto, B. Klumperman, A. B. Lowe, J. B. McLeary, G. Moad, M. J. Monteiro, R. D. Sanderson, M. P. Tonge and P. Vana, J. Polym. Sci., Part A: Polym. Chem., 2006, 44, 5809-5831.

50 G. Moad, Macromol. Chem. Phys., 2014, 215, 9-26.

51 A. Blanazs, J. Madsen, G. Battaglia, A. J. Ryan and S. P. Armes, J. Am. Chem. Soc., 2011, 133, 16581-16587.

52 A. Blanazs, R. Verber, O. O. Mykhaylyk, A. J. Ryan, J. Z. Heath, C. W. I. Douglas and S. P. Armes, J. Am. Chem. Soc., 2012, 134, 9741-9748.

53 J. Madsen, S. P. Armes, K. Bertal, S. MacNeil and A. L. Lewis, Biomacromolecules, 2009, 10, 1875-1887.

54 S. F. Lascelles, F. Malet, R. Mayada, N. C. Billingham and S. P. Armes, Macromolecules, 1999, 32, 2462-2471.

55 A. B. Lowe, N. C. Billingham and S. P. Armes, Chem. Commun., 1996, 1555-1556.

56 Z. Zhu, J. Xu, Y. Zhou, X. Jiang, S. P. Armes and S. Liu, Macromolecules, 2007, 40, 6393-6400. 